\title{
CARACTERÍSTICAS FÍSICO-QUÍMICAS E PRODUTIVAS DA VIDEIRA 'BRS CLARA' SOB CULTIVO PROTEGIDO'
}

\author{
LARISSA ABGARIANI COLOMBO ${ }^{2}$, SÉRGIO RUFFO ROBERTO 3 , DAURI JOSÉ TESSMANN 4 , \\ WERNER GENTA 5 , ALESSANDRO JEFFERSON SATO², ADRIANE MARINHO DE ASSIS ${ }^{2}$
}

RESUMO - Atualmente, a preferência por uvas sem sementes vem aumentando nos mercados interno e externo, sendo uma alternativa a produção de uvas sob cultivo protegido. No entanto, o custo de produção de uvas finas para mesa tem sido afetado pela intensa necessidade de controle de doenças fúngicas, como o míldio (Plasmopara viticola). O trabalho teve como objetivo avaliar a produção e as características físicoquímicas dos frutos da videira 'BRS Clara' sobre os porta-enxertos 'IAC 572 Jales' e 'IAC 766 Campinas', sob diferentes tipos de cultivo protegido. O experimento foi realizado no município de Marialva-PR, durante duas safras regulares (set.-dez.2007, ago-dez.2008). O delineamento experimental foi o de blocos ao acaso, com quatro repetições, em arranjo fatorial 7 x 2 (sete tipos de cultivo protegido e dois porta-enxertos). Os tratamentos foram os seguintes tipos de cultivo: $a$. tela plástica sem fungicidas para míldio; $b$. tela plástica com fungicidas para míldio (padrão de controle da região); $c$. cobertura plástica sem fungicidas para míldio; $d$. cobertura plástica e $50 \%$ de redução do padrão de fungicidas para míldio; $e$. cobertura plástica e $75 \%$ de redução do padrão de fungicidas para míldio; $f$. cobertura plástica com fosfito e cobre, e $g$. cobertura plástica sem fungicidas. Verificou-se que o cultivo protegido não alterou as características produtivas da videira 'BRS Clara', como número de cachos e produção por planta; os porta-enxertos 'IAC 766' e 'IAC 572' são indicados para a produção da uva 'BRS Clara', e a utilização da cobertura plástica permite a redução do número de aplicações de fungicidas para míldio no cultivo da uva 'BRS Clara'.

Termos para indexação: Viticultura, cobertura plástica, uva apirena, produção de frutos.

\section{PHYSICAL-CHEMICAL AND PRODUCTIVE CHARACTERISTICS OF 'BRS CLARA' UNDER PROTECTED CULTIVATION}

\begin{abstract}
Currently the preference for seedless grapes is increasing in domestic and foreign markets and an alternative is to produce grapes under plastic cover. However, the increased costs of production of table grapes has been affected by the intense need to control fungal diseases such as downy mildew (Plasmopara viticola). The study aimed to evaluate the production and physicochemical characteristics of 'BRS Clara' seedless grape on 'IAC 572 Jales' and 'IAC 766 Campinas' rootstocks, under different kinds of protected cultivation. The experiment was conducted in Marialva-PR, during two regular crops (Sep-Dec/2007, AugDec/2008). The randomized block design was used as a statistical model with four replications arranged in a factorial 7 x 2 (seven kinds of protected cultivation and two rootstocks). The treatments were the following types of cultivation: $a$. plastic screen without fungicides for downy mildew; $b$. plastic screen with fungicides for downy mildew (standard control of the region); $c$. plastic cover without fungicides for downy mildew; $d$. plastic cover and $50 \%$ of reduction of the standard control for downy mildew; $e$. plastic cover and $75 \%$ of reduction for the standard fungicide for downy mildew; $f$. plastic cover with phosphite and copper; and $g$. plastic cover without fungicides. It was found that the protected cultivation did not alter the productive characteristics of the vine 'BRS Clara', as the number of clusters and production per plant; the 'IAC 766' and 'IAC 572' rootstocks are suitable for the production of the grape 'BRS Clara' and; the use of plastic cover allows reducing the number of applications of fungicides for downy mildew in the cultivation of the grape 'BRS Clara'.
\end{abstract}

Index terms: Viticulture, plastic sheeting, seedless grape, fruit production.

\footnotetext{
'(Trabalho 182-10). Recebido em: 30-07-2010. Aceito para publicação em: 21-12-2010. Projeto financiado pelo CNPq, Processo $552541 / 2006$.

${ }^{2}$ Alunos de Pós-Graduação em Agronomia/Fitotecnia, Universidade Estadual de Londrina, Caixa Postal 6001, 86051-990, Londrina/ Paraná, E-mail: labgariani@ig.com.br

${ }^{3}$ Eng. Agr ${ }^{\circ}$, Dr. Professor Associado, Departamento de Agronomia/Fitotecnia, Universidade Estadual de Londrina, Caixa Postal 6001, 86051-990, Londrina/Paraná, E-mail: sroberto@uel.br

${ }^{4}$ Eng. Agr ${ }^{\circ}$, Dr. Professor Associado, Departamento de Agronomia/Fitopatologia, Universidade Estadual de Maringá. Maringá/Paraná, E-mail: djtessmann@uem.br

${ }^{5}$ Aluno de Pós-Graduação em Agronomia/Fitopatologia, Universidade Estadual de Maringá. Maringá/Paraná, e-mail: werner@isuper.com.br
} 


\section{INTRODUÇÃO}

No Estado do Paraná, a viticultura ocupa área de 5,8 mil hectares, com produção de aproximadamente 101 mil toneladas de uva, sendo a região nortenoroeste responsável por aproximadamente $20 \%$ do total da área cultivada com uvas para mesa no Brasil e 50\% do total da área no Estado (KISHINO et al., 2007). No comércio internacional da uva para mesa, a tendência é a demanda por uvas sem sementes que, rapidamente, vêm conquistando consumidores europeus, porém a produção no Brasil é ainda pequena (ARAÚJO, 2004; NACHTIGAL, 2005).

A uva sem semente 'BRS Clara', lançada pela Embrapa Uva e Vinho, tornou-se recentemente uma boa opção no norte do Paraná. Além de vigorosa e fértil, possui produtividade elevada (30t/ha/ano), e os cachos apresentam boa conformação. A uva destaca-se pelo suave e agradável sabor moscatel, pela coloração verde-amarelada das bagas e textura crocante da polpa (CAMARGO et al., 2003).

As regiões brasileiras produtoras de uvas finas para mesa, inclusive a do Paraná, vêm passando por alguns desafios, como o aumento dos custos de produção das principais variedades cultivadas, devido à intensa necessidade de controle de algumas doenças fúngicas, como o míldio (Plasmopara viticola), que pode causar perdas de até $100 \%$ da produção. No norte do Paraná, todas as cultivares de uvas finas para mesa produzidas apresentam alta suscetibilidade ao míldio, afetando a longevidade, a produtividade e a qualidade do fruto da videira. A intensidade dos danos provocados pelo míldio está relacionada à cultivar, ao clima, à época do ano em que ocorre o ciclo de cultivo, ao sistema de produção empregado e aos tratos culturais realizados (TESSMANN et al., 2007).

O sistema de produção de uvas sob cobertura plástica pode melhorar a qualidade das uvas, pois evita o molhamento da parte aérea da planta e diminui a incidência de fungos patogênicos, sobretudo o míldio, permitindo a redução ou a eliminação do uso de defensivos químicos (TAGLIARI, 2003; CHAVARRIA et al., 2007). Além disso, possibilita modificações nas variáveis do microclima, principalmente na temperatura, na radiação e nos ventos (CARDOSO et al., 2008). Essas alterações podem modificar as respostas fisiológicas da videira, sendo, em alguns casos, fator atenuante de estresses hídricos e promotor de melhores condições para o crescimento da planta (CHAVARRIA et al., 2008).

Considerando esses aspectos, este trabalho teve como objetivo avaliar a produção e as características físico-químicas dos frutos da videira 'BRS
Clara', sobre os porta-enxertos 'IAC 572 Jales' e 'IAC 766 Campinas', submetida a diferentes tipos de cultivo protegido, durante duas safras regulares.

\section{MATERIAL E MÉTODOS}

O trabalho foi conduzido em uma área experimental localizada no município de Marialva

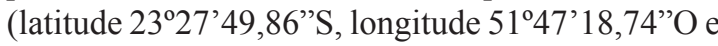
altitude 614 metros), no norte do Estado do Paraná, durante as safras de 2007 e 2008 . Foram utilizados dois porta-enxertos ('IAC 766 Campinas' e 'IAC 572 Jales') e a cultivar de uva sem semente BRS Clara. O plantio dos porta-enxertos e a enxertia da variedade copa foram realizados em julho de 2004 e julho de 2005, respectivamente, utilizando-se de material propagativo livre de vírus obtidos na Embrapa Uva e Vinho, Bento Gonçalves-RS.

As videiras foram conduzidas no sistema latada, no espaçamento de $3,0 \mathrm{~m}$ entre linhas e $4,0 \mathrm{~m}$ entre plantas. As podas foram realizadas nas varas formadas, eliminando-se as gemas da ponta, deixando-se 6 a 9 gemas/vara, sendo que apenas duas ou três gemas da extremidade destas varas foram estimuladas a brotar, aplicando-se cianamida hidrogenada a 2,5\%. As datas de poda e colheita de cada safra avaliada foram: safra 2007 - poda em 04-09-2007 e colheita em 19-12-2007, e safra 2008 - poda em 28-08-2008 e colheita em 18-12-2008.

O delineamento experimental foi o de blocos ao acaso, com quatro repetições, em arranjo fatorial 7 × 2 (sete tipos de cultivo protegido e dois portaenxertos), sendo cada parcela composta por uma planta útil. Os tratamentos foram os seguintes tipos de cultivo protegido: $a$. Tela plástica sem fungicidas para míldio; $b$. Tela plástica com fungicidas para míldio (padrão de controle da região); $c$. Cobertura plástica sem fungicidas para míldio; $d$. Cobertura plástica e $50 \%$ de redução do padrão de controle para míldio; $e$. Cobertura plástica e $75 \%$ de redução do padrão de controle para míldio; $f$. Cobertura plástica com fosfito e cobre, e $g$. Cobertura plástica sem fungicidas.

Nos tratamentos $a$ e $b$, foi empregada tela plástica no sistema de capela, na coloração preta, com $18 \%$ de sombreamento, totalizando 10 fileiras cobertas, e nos tratamentos $c, d, e, f$ e $g$, foram utilizadas lonas plásticas trançadas de polipropileno, impermeabilizada com polietileno de baixa densidade (15 a $20 \%$ de sombreamento), com $2,70 \mathrm{~m}$ de largura e 150 $\mu$ de espessura, aditivadas contra raios ultravioleta, aplicadas sobre estrutura composta por fios metálicos esticados entre arcos de ferro galvanizado de $3,0 \mathrm{~m}$, dispostos ao longo da linha de plantio, totalizando 10 
fileiras cobertas, instalados sobre o parreiral a cada $2,0 \mathrm{~m}$ instalados sobre postes de eucalipto. No espaço entre as linhas de plantio, permaneceram aberturas de aproximadamente $0,30 \mathrm{~m}$ que, posteriormente, foram adaptadas com uma estrutura do mesmo material da cobertura plástica, denominada calha, para que a água da chuva pudesse atingir apenas o sistema radicular das plantas, sem molhar o dossel vegetativo.

O sistema de controle-padrão da região (tratamento $b$ ) foi aplicado utilizando-se dos seguintes defensivos de forma intercalada, em um total de três a quatro aplicações a cada sete dias, tendo como alvo o míldio, a antracnose e o oídio (dose para 100L, seguido do nome do ingrediente ativo): 0,20kg (Metiram+Piraclostrobina); $0,25 \mathrm{~kg}$ (Cymoxanil+Mancozeb); 0,06kg ( C y m ox ani $1+\mathrm{M}$ a n c oz e b ); $0,25 \mathrm{~kg}$ (Metalaxil+Mancozeb); 0,03L (Fenamidone); $0,25 \mathrm{~kg}$ (Iprovalicarbe+Propinebe); $0,12 \mathrm{~kg}$ (Famoxadona+Mancozeb); 0,3kg (Mancozeb); 0,18kg (Hidróxido de Cobre); 0,012L (Difenoconazole); $0,07 \mathrm{~kg}$ (Tiofanato Metílico); 0,02L (Fenarimol) e $0,24 \mathrm{~kg}$ (Captan). Para o tratamento $f$, utilizaram-se duas a três aplicações, a cada sete dias, dos produtos (dose para 100L, seguido do nome do ingrediente ativo entre parênteses): 0,3L (Fosfito de Potássio) e 0,18kg (Hidróxido de Cobre). As aplicações foram realizadas no início da brotação e estenderam-se até 15 dias antes da colheita, sendo feitas através de pulverizador costal equipado com motor elétrico e válvula de pressão constante.

Nos tratamentos $a, b, c, d$, e e $f$, foram aplicados fungicidas para o controle de oídio, e nos tratamentos $d$ e $e$, o número de aplicações de fungicidas para controle do míldio foi reduzido em 50 e $75 \%$, respectivamente, em relação ao número de aplicações empregado no tratamento fitossanitário padrão da região (tratamento $b$ ). Ressalta-se que o número de pulverizações com fungicidas variou entre as duas safras, tendo em vista que as condições meteorológicas foram distintas nos dois anos agrícolas. Foram realizadas para os tratamentos $a$, $b, c, d, e, f$ e $g$ os seguintes números de aplicações de fungicidas, respectivamente: $0 ; 42 ; 8 ; 22 ; 10 ; 11$ e 0 na safra de 2007 e $0 ; 45 ; 9 ; 21 ; 18 ; 13$ e 0 na safra de 2008.

As variáveis meteorológicas, como precipitação (mm) e molhamento foliar no escuro (h), foram obtidas nos ambientes abaixo da tela plástica e da cobertura plástica e fora do parreiral, a partir de três estações micrometeorológicas Metos (Pessl Instruments, Áustria). As estações foram programadas a coletar os dados das variáveis climáticas a cada 12 minutos, com o objetivo de verificar a sua influência sobre o desenvolvimento das plantas e a intensidade das doenças (CARDOSO et al., 2008).

Foram avaliadas as seguintes variáveis: número de varas por planta, número de gemas por planta, gemas brotadas por planta $(\%)$, fertilidade de gemas $(\%)$, número de cachos por planta e por $\mathrm{m}^{2}$, comprimento dos cachos (cm), massa dos cachos (kg) e das bagas (g), produção por planta (kg/planta), produtividade ( $\mathrm{t} / \mathrm{ha})$, teor de sólidos solúveis $(\mathrm{SS})$, acidez titulável (AT) e índice de maturação (SS/AT). O comprimento dos cachos foi quantificado com o auxílio de uma régua graduada, e a massa dos cachos e das bagas, em balança analítica. Para a colheita dos cachos, efetuou-se uma amostragem de bagas para avaliar o teor de SS, expresso em ${ }^{\circ}$ Brix, através de leitura em refratômetro manual. Os cachos foram colhidos manualmente, quando apresentaram 18 a $19^{\circ}$ Brix, com auxílio de tesoura de colheita, sendo posteriormente submetidos à limpeza, retirando-se folhas ou ramos contidos entre as bagas, bagas danificadas, podres ou picadas por insetos.

Foram analisados por repetição cinco cachos quanto ao comprimento, 10 bagas quanto à massa e 10 bagas para a extração de suco para a leitura do teor de SS. Quanto às características químicas das bagas, o teor de SS foi determinado em refratômetro digital de bancada com compensação automática de temperatura (Modelo DR301-95, Krüss Optronic, Alemanha), através do mosto obtido após o desengace e esmagamento das bagas, e o resultado foi expresso em ${ }^{\circ}$ Brix. A determinação da AT foi realizada por titulação do suco com solução padronizada de $\mathrm{NaOH} 0,1 \mathrm{~N}$ em titulador potenciométrico digital (Modelo Tritoline Easy, Schott Geräte, Alemanha), e o resultado foi expresso em porcentagem de ácido tartárico.

A produção e as características físico-químicas de cada safra foram analisadas por meio da análise de variância, e a separação das médias foi realizada pelo teste de Tukey, a 5\% de probabilidade, no aplicativo SISVAR, versão 4.3 (FERREIRA, 2000).

A porcentagem de ocorrência de míldio nos cachos foi avaliada a partir do início do enchimento das bagas, sendo a última avaliação realizada uma semana antes da colheita, através de amostragem em quatro ramos por parcela, dois de cada lado da planta, com um cacho por ramo, perfazendo quatro cachos (MADDEN et al., 2000). Os dados foram submetidos à análise de variância, e a separação das médias foi realizada pelo teste Scott-Knott, a $1 \%$ de probabilidade, utilizando o aplicativo SISVAR, versão 4.3 (FERREIRA, 2000). 


\section{RESULTADOS E DISCUSSÃO}

Para as variáveis número de varas e gemas por planta, porcentagem de gemas brotadas por planta e porcentagem de fertilidade de gemas, não houve interação significativa entre os fatores estudados (tipos de cultivo protegido e porta-enxertos) nas duas safras (Tabela 1). Os números médios de varas e gemas deixados por planta foram, respectivamente, 41 e 83, na safra de 2007, e 37 e 76, na safra de 2008. Mota et al. (2008), avaliando videiras de 'Cabernet Sauvignon', em Caxias do Sul-RS, também não observaram efeito do ambiente de cultivo (cobertura plástica e sem cobertura) nos números de varas e gemas por planta, que foram em média $26 \mathrm{e}$ 41 , respectivamente.

Na safra de 2007, a porcentagem de gemas brotadas e a fertilidade de gemas foi, em média, $58,0 \%$ e $47,2 \%$, respectivamente. Porém, deve ser considerado que, por se tratar de brotação oriunda da poda seca, os resultados obtidos enquadraram-se dentro de valores comuns àqueles observados em anos em que o inverno não é rigoroso na região, ainda que tenha sido aplicado o regulador cianamida hidrogenada nas gemas. Além disso, deve ser ressaltado que essa porcentagem de brotação se deu no primeiro ciclo produtivo da videira, período em que as plantas precisam de um período de adaptação para se estabelecer.

No que se refere à fertilidade de gemas, na safra de 2007, houve diferença significativa apenas entre os porta-enxertos. O uso do 'IAC 766' resultou em média superior àquela do 'IAC 572 ' (55,6 e 38,8\%, respectivamente). Isso ocorreu porque as plantas enxertadas sobre o 'IAC 572' emitiram ramos muito vigorosos, prejudicando a produção, como também observado por Feldberg et al. (2007), que constataram que o mesmo portaenxerto induziu menor fertilidade das gemas e de cachos, e, consequentemente, menor produção das plantas de 'Crimson Seedless' e 'Superior Seedless', em Mocambinho-MG. Em relação às características da brotação, não houve interferência dos tipos de cultivo protegido nas duas safras avaliadas.

Em relação ao número de cachos por planta e por unidade de área, massa e comprimento dos cachos e massa das bagas, não foram observadas interações significativas entre porta-enxerto e tipo de cultivo protegido.

Ainda, não houve influência do tipo de cultivo protegido sobre essas variáveis; entretanto, observaram-se diferenças significativas entre os porta-enxertos (Tabela 2). Na safra de 2007, as plantas enxertadas sobre o 'IAC 766' apresentaram médias superiores (31,7 cachos/planta, 2,6 cachos $/ \mathrm{m}^{2}$ e cachos com $0,5 \mathrm{~kg}$ e $18,1 \mathrm{~cm}$ de comprimento) em relação às plantas enxertadas sobre o 'IAC 572' (20,1 cachos/planta, 1,6 cachos $/ \mathrm{m}^{2}$ e cachos com $0,4 \mathrm{~kg}$ e $15,9 \mathrm{~cm}$ de comprimento). Somente em relação à massa das bagas, plantas com o porta-enxerto 'IAC 572 ' foram superiores $(5,3 \mathrm{~g})$ àquelas com o 'IAC 766' $(5,0 \mathrm{~g})$. Na safra de 2008 , no que diz respeito à massa das bagas, as plantas enxertadas sobre o 'IAC 572' obtiveram média superior às enxertadas sobre o 'IAC $766^{\prime}$ ( 5,1 e $4,8 g$, respectivamente), enquanto para as demais variáveis não foram observadas diferenças em relação aos porta-enxertos.

Trabalhando com o porta-enxerto 'IAC 766', no município de Sento Sé-BA, durante dois ciclos de produção, Leão (2002) obteve valores médios de massa das bagas de 4,5g, 30,5 cachos/planta, cachos com $0,34 \mathrm{~kg}$ e $20,4 \mathrm{~cm}$ de comprimento com as variedades de uva sem sementes Crimson Seedless e Fantasy Seedless. Com a uva 'Romana' (A1105), em Jundiaí-SP, Lulu et al. (2005) observaram menor massa de cacho em plantas descobertas que em plantas cobertas, o que, segundo os autores, pode estar relacionado ao maior murchamento e perda de bagas, ocasionado por doenças fúngicas. Com a videira 'Cabernet Sauvignon' em Caxias do Sul, Mota et al. (2008) verificaram que o número de cachos por planta não foi influenciado pelos tratamentos com e sem cobertura, e obtiveram em média 22,4 cachos/planta.

Quanto à produção por planta e produtividade (Tabela 3), não foi observado, na safra de 2007, interação entre os fatores estudados, nem mesmo diferença entre os tipos de cultivo protegido. Entretanto, a produção por planta e a produtividade da 'BRS Clara' sobre o 'IAC 766' foram significativamente superiores $(15,1 \mathrm{~kg} / \mathrm{planta}$ e $12,6 \mathrm{t} / \mathrm{ha}$, respectivamente) aos resultados do 'IAC 572'. Essas médias podem ser consideradas baixas quando levado em consideração o potencial produtivo da videira 'BRS Clara' (CAMARGO et al., 2003). Entretanto, é importante salientar que estes resultados referem-se ao primeiro ano de produção e que o vinhedo se encontrava em fase de adaptação.

Na safra de 2008, também não houve interação entre porta-enxertos e tipos de cultivo protegido quanto à produção por planta e produtividade, com médias em torno de $23 \mathrm{~kg} / \mathrm{planta}$ e $19 \mathrm{t} / \mathrm{ha}$, respectivamente. Entretanto, as médias foram consideradas altas para todos os tratamentos, exceto para a tela plástica sem fungicidas, em que não foi obtida produção alguma, e para plástico sem fungicidas, em que as médias $(18,9 \mathrm{~kg} /$ planta e $15,7 \mathrm{t} / \mathrm{ha}$ ) foram significativamente inferiores ao tratamento plástico com 50\% de redução do padrão (Tabela 3). Nos tratamentos em que 
se reduziu em 50 e $75 \%$ o número de aplicações de fungicidas em relação ao padrão da região, as médias mantiveram-se equivalentes ao tratamento-padrão, o que mostra a contribuição do uso da cobertura plástica para a redução do uso de fungicidas para o controle do míldio na videira 'BRS Clara'. Nessa safra, o tratamento plástico com fosfito de potássio e cobre, também, resultou em médias semelhantes aos tratamentos com cobertura plástica e redução de 50 e $75 \%$ do número de aplicação de fungicidas. Resultados obtidos por Chavarria et al. (2007) também evidenciaram a eficiência do uso da cobertura plástica na diminuição da dosagem e na aplicação de fungicidas, proporcionando a diminuição de custos e de resíduos em cultivos protegidos. Ferreira et al. (2004), em estudo semelhante com a videira 'Cabernet Sauvignon', em Jundiaí-SP, verificaram que não houve diferenças significativas entre os ambientes estudados (cobertura plástica e a céu aberto) nem mesmo entre os porta-enxertos ('IAC 572' e 'IAC $766^{\prime}$ ). Porém, os valores médios obtidos em um ciclo de produção $(1,2 \mathrm{~kg} /$ planta e $1,5 \mathrm{~kg} /$ planta, respectivamente) mostraram-se inferiores aos observados no presente trabalho. Em experimento empregando-se o 'IAC 766', no município de Sento Sé-BA, Leão (2002) obteve produção média durante dois ciclos de produção de 13,0 e 7,2kg/planta para as uvas sem sementes 'Crimson Seedless' e 'Fantasy Seedless', respectivamente.

Não foi observada interação entre os fatores quanto às características químicas das bagas, nem mesmo diferenças entre os tipos de cultivo protegido, na safra de 2007 (Tabela 4). Observou-se alto teor de SS para a videira 'BRS Clara', independentemente do porta-enxerto, que em média atingiu $19^{\circ}$ Brix. Entre os porta-enxertos, verificou-se que houve diferenças significativas para a AT nas bagas, onde a média da 'BRS Clara' sobre o 'IAC 572' foi superior ao 'IAC 766' (1,6 e 1,2\% de ácido tartárico, respectivamente). Para a relação SS/AT, a média da 'BRS Clara' sobre o 'IAC 766' foi superior à 'BRS Clara' sobre o 'IAC 572' (19,1 e 12,3, respectivamente). Na safra de 2008, em relação à AT (Tabela 4), a menor média foi observada para o tratamento plástico com fosfito de potássio e cobre ( $0,5 \%$ de ácido tartárico), e as maiores médias, observadas para os tratamentos tela plástica com fungicidas (padrão) $(0,7 \%$ de ácido tartárico) e plástico sem fungicidas para míldio $(0,7 \%$ de ácido tartárico). Na safra de 2007, as uvas apresentaram níveis de AT superiores aos obtidos na safra de 2008, fato também observado por Chavarria et al. (2010) em estudo com uvas 'Moscato Giallo', no município de Flores da Cunha-RS. Vale ressaltar que a evolução da acidez do mosto da uva ocorre, principalmente, em função da degradação do ácido málico, favorecida pela temperatura do ar mais elevada e pelo estágio de maturação da uva.

Na safra de 2007, não se constatou míldio nas videiras. Acredita-se que isso foi devido às condições meteorológicas desfavoráveis ao progresso da doença. A quantidade e a intensidade da precipitação pluviométrica, assim como a ocorrência de molhamento foliar no escuro foram baixas (Figura 1). A falta de umidade foi mais limitante para a ocorrência de míldio do que a temperatura do ambiente, uma vez que as temperaturas médias registradas fora do vinhedo, no plástico e na tela plástica, foram de 22,$8 ; 23,4$ e $23,2^{\circ} \mathrm{C}$, respectivamente, as quais são consideradas favoráveis ao progresso da doença.

Na safra de 2008, foi observada a ocorrência de míldio nos cachos das videira. Entretanto, verifica-se que os porta-enxertos não exerceram influência na ocorrência de míldio na videira 'BRS Clara'. Os tratamentos com cobertura plástica, com ou sem fungicidas, não diferiram significativamente entre si, e também não diferiram significativamente do tratamento tela plástica com fungicidas para míldio, em que foram observados $100 \%$ dos cachos com ocorrência da doença (Tabela 5). O emprego de cobertura plástica permitiu a redução de até $75 \%$ do número de aplicações de fungicidas, sem prejuízo à eficiência agronômica dos tratamentos. Independentemente do sistema de cultivo protegido, durante essa safra na região, as condições meteorológicas foram mais favoráveis, devido à maior frequência $\mathrm{e}$ intensidade de chuvas e de períodos prolongados de molhamento foliar (Figura 1), além das temperaturas médias registradas fora do parreiral, no plástico e na tela plástica, que foram de 20,$6 ; 21,7$ e $21,7^{\circ} \mathrm{C}$, respectivamente.

Pelos resultados obtidos durante as safras de 2007 e 2008, o emprego da cobertura plástica permite reduzir em até $75 \%$ o número de aplicações de fungicidas, sem prejudicar as características físico-químicas e produtivas da videira 'BRS Clara', demonstrando ser uma tecnologia promissora, devido à redução nos custos de aplicação de fungicidas, tornando-se competitiva a produção de uvas sem sementes na região norte do Paraná. Entretanto, ressalta-se que o cultivo protegido é um novo sistema de produção de uvas de mesa, porém com pontos importantes que devem ser levados em consideração, como os custos, e também à menor durabilidade do plástico, em média três anos, quando comparado à tela plástica. 
TABELA 1 - Características da brotação da videira 'BRS Clara' sobre os porta-enxertos 'IAC 572 Jales' e 'IAC 766 Campinas', submetida a diferentes tipos de cultivo protegido e de tratamento fitossanitário, durante as safras de 2007 e 2008. Marialva-PR.

\begin{tabular}{|c|c|c|c|c|}
\hline \multirow[b]{2}{*}{ Porta-enxertos (PE) } & \multicolumn{4}{|c|}{ SAFRA 2007} \\
\hline & $\begin{array}{l}\mathrm{n}^{\circ} \text { de varas/ } \\
\text { planta }\end{array}$ & $\begin{array}{l}n^{\circ} \text { de gemas/ } \\
\text { planta }\end{array}$ & $\begin{array}{c}\% \text { de gemas } \\
\text { brotadas/planta }\end{array}$ & $\begin{array}{c}\text { fertilidade de } \\
\text { gemas }(\%)\end{array}$ \\
\hline 'IAC 572 Jales' & 42,2 a & 84,3 a & 58,5 a & $38,8 \mathrm{~b}$ \\
\hline 'IAC 766 Campinas’ & 41,3 a & 82,6 a & 57,6 a & 55,6 a \\
\hline \multicolumn{5}{|l|}{ Tipos de Cultivo Protegido (TC) } \\
\hline Tela plástica sem fungicidas para míldio ${ }^{\mathrm{a} /}$ & $45,1 \mathrm{a}$ & 90,2 a & 55,9 a & 55,7 a \\
\hline Tela plástica com fungicidas (padrão) ${ }^{\mathrm{a} /}$ & 40,2 a & 80,5 a & 58,1 a & $45,7 \mathrm{a}$ \\
\hline Plástico sem fungicidas para míldio ${ }^{\mathrm{a} /}$ & 40,7 a & 81,5 a & 60,0 a & 49,4 a \\
\hline Plástico com 50\% redução do padrão ${ }^{a /}$ & 38,4 a & 76,7 a & 57,3 a & 41,9 a \\
\hline Plástico com $75 \%$ redução do padrão ${ }^{a /}$ & 45,1 a & 90,2 a & 59,2 a & 44,6 a \\
\hline Plástico com fosfito e cobre ${ }^{a /}$ & 40,9 a & 81,7 a & $61,1 \mathrm{a}$ & 45,5 a \\
\hline Plástico sem fungicidas & $41,7 \mathrm{a}$ & 83,5 a & $54,5 \mathrm{a}$ & $47,7 \mathrm{a}$ \\
\hline \multirow[t]{2}{*}{$\mathrm{CV} \%$} & 19,00 & 19,00 & 18,35 & 27,21 \\
\hline & \multicolumn{4}{|c|}{ SAFRA 2008} \\
\hline Porta-enxertos (PE) & $\begin{array}{l}n^{\circ} \text { de varas/ } \\
\text { planta }\end{array}$ & $\begin{array}{l}\text { no de gemas/ }^{\circ} \\
\text { planta }\end{array}$ & $\begin{array}{c}\% \text { de gemas } \\
\text { brotadas/planta }\end{array}$ & $\begin{array}{l}\text { fertilidade de } \\
\text { gemas }(\%)\end{array}$ \\
\hline 'IAC 572 Jales' & $37,0 \mathrm{a}$ & $74,1 \mathrm{a}$ & 90,9 a & $68,3 \mathrm{a}$ \\
\hline 'IAC 766 Campinas’ & $37,4 \mathrm{a}$ & $78,7 \mathrm{a}$ & $92,2 \mathrm{a}$ & $73,2 \mathrm{a}$ \\
\hline \multicolumn{5}{|l|}{ Tipos de Cultivo Protegido (TC) } \\
\hline Tela plástica sem fungicidas para míldio ${ }^{\mathrm{a} /}$ & $39,0 \mathrm{a}$ & $78,0 \mathrm{a}$ & $83,67 \mathrm{a}$ & $80,9 \mathrm{a}$ \\
\hline Tela plástica com fungicidas (padrão) ${ }^{a /}$ & $38,1 \mathrm{a}$ & 76,3 a & 88,9 a & $69,4 \mathrm{a}$ \\
\hline Plástico sem fungicidas para míldio ${ }^{a /}$ & $37,0 \mathrm{a}$ & $88,8 \mathrm{a}$ & $96,2 \mathrm{a}$ & $64,8 \mathrm{a}$ \\
\hline Plástico com $50 \%$ redução do padrão ${ }^{a /}$ & $37,3 \mathrm{a}$ & 73,8 a & 93,3 a & $67,6 \mathrm{a}$ \\
\hline Plástico com $75 \%$ redução do padrão ${ }^{a /}$ & $35,6 \mathrm{a}$ & $71,3 \mathrm{a}$ & $88,4 \mathrm{a}$ & $72,8 \mathrm{a}$ \\
\hline Plástico com fosfito e cobre ${ }^{a /}$ & 35,6 a & $71,3 \mathrm{a}$ & 97,3 a & $74,7 \mathrm{a}$ \\
\hline Plástico sem fungicidas & $37,8 \mathrm{a}$ & $75,5 \mathrm{a}$ & $93,5 \mathrm{a}$ & $65,1 \mathrm{a}$ \\
\hline CV\% & 13,97 & 25,08 & 11,68 & 21,16 \\
\hline
\end{tabular}

${ }^{\mathrm{a} /}$ : Com fungicidas para oídio.

Médias seguidas da mesma letra nas colunas não diferem entre si, pelo teste de Tukey $(p<0,05)$. 
TABELA 2 - Características dos cachos da videira 'BRS Clara' sobre os porta-enxertos 'IAC 572 Jales' e 'IAC 766 Campinas', submetida a diferentes tipos de cultivo protegido e de tratamento fitossanitário, durante as safras de 2007 e 2008. Marialva-PR.

\begin{tabular}{|c|c|c|c|c|c|}
\hline \multirow[b]{2}{*}{ Porta-enxertos (PE) } & \multicolumn{5}{|c|}{ SAFRA 2007} \\
\hline & $\begin{array}{c}n^{\circ} \text { de } \\
\text { cachos/ } \\
\text { planta }\end{array}$ & $\begin{array}{c}\mathbf{n}^{\circ} \text { de } \\
\text { cachos/ } \\
\mathbf{m}^{2}\end{array}$ & $\begin{array}{c}\text { massa dos } \\
\text { cachos } \\
(\mathrm{kg})\end{array}$ & $\begin{array}{c}\text { comprimento } \\
\text { dos cachos } \\
(\mathbf{c m})\end{array}$ & $\begin{array}{c}\text { massa das } \\
\text { bagas } \\
\text { (g) }\end{array}$ \\
\hline 'IAC 572 Jales' & $20,1 \mathrm{~b}$ & $1,6 \mathrm{~b}$ & $0,4 \mathrm{~b}$ & $15,9 \mathrm{~b}$ & 5,3 a \\
\hline 'IAC 766 Campinas' & $31,7 \mathrm{a}$ & $2,6 \mathrm{a}$ & $0,5 \mathrm{a}$ & $18,1 \mathrm{a}$ & $5,0 \mathrm{~b}$ \\
\hline \multicolumn{6}{|l|}{ Tipos de Cultivo Protegido (TC) } \\
\hline Tela plástica sem fungicidas para míldio ${ }^{\mathrm{a}}$ & 33,0 a & $2,7 \mathrm{a}$ & 0,4 a & 17,1 a & $5,2 \mathrm{a}$ \\
\hline Tela plástica com fungicidas (padrão) ${ }^{a /}$ & 23,5 a & $1,9 \mathrm{a}$ & 0,4 a & 17,5 a & $4,9 \mathrm{a}$ \\
\hline Plástico sem fungicidas para míldio ${ }^{\mathrm{a} /}$ & $26,7 \mathrm{a}$ & $2,2 \mathrm{a}$ & 0,4 a & 16,3 a & $5,2 \mathrm{a}$ \\
\hline Plástico com $50 \%$ redução do padrão ${ }^{a /}$ & 23,2 a & $1,9 \mathrm{a}$ & $0,4 \mathrm{a}$ & $16,7 \mathrm{a}$ & 5,1 a \\
\hline Plástico com $75 \%$ redução do padrão ${ }^{a /}$ & 25,5 a & $2,1 \mathrm{a}$ & 0,4 a & 16,9 a & 5,2 a \\
\hline Plástico com fosfito e cobre ${ }^{a /}$ & 25,0 a & $2,1 \mathrm{a}$ & 0,4 a & 17,0 a & $5,3 \mathrm{a}$ \\
\hline$\underline{\text { Plástico sem fungicidas }}$ & 24,2 a & $1,9 \mathrm{a}$ & $0,4 \mathrm{a}$ & $17,5 \mathrm{a}$ & $5,2 \mathrm{a}$ \\
\hline \multirow[t]{2}{*}{$\mathrm{CV} \%$} & 29,57 & 28,35 & 28,49 & 9,45 & 9,37 \\
\hline & \multicolumn{5}{|c|}{ SAFRA 2008} \\
\hline Porta-enxertos (PE) & $\begin{array}{c}\mathbf{n}^{\circ} \text { de } \\
\text { cachos/ } \\
\text { planta }\end{array}$ & $\begin{array}{c}\mathbf{n}^{\circ} \text { de } \\
\text { cachos/ } \\
\mathbf{m}^{2}\end{array}$ & $\begin{array}{c}\text { massa dos } \\
\text { cachos } \\
(\mathrm{kg})\end{array}$ & $\begin{array}{c}\text { comprimento } \\
\text { dos cachos } \\
(\mathbf{c m})\end{array}$ & $\begin{array}{c}\text { massa das } \\
\text { bagas } \\
(\mathrm{g}) \\
\end{array}$ \\
\hline 'IAC 572 Jales' & $50,8 \mathrm{a}$ & $4,23 \mathrm{a}$ & $0,50 \mathrm{a}$ & $21,7 \mathrm{a}$ & $5,1 \mathrm{a}$ \\
\hline 'IAC 766 Campinas' & $55,3 \mathrm{a}$ & $4,61 \mathrm{a}$ & $0,43 \mathrm{a}$ & $21,3 \mathrm{a}$ & $4,8 \mathrm{~b}$ \\
\hline \multicolumn{6}{|l|}{ Tipos de Cultivo Protegido (TC) } \\
\hline Tela plástica sem fungicidas para míldio ${ }^{a /}$ & - & - & - & - & - \\
\hline Tela plástica com fungicidas (padrão) ${ }^{a /}$ & $57,4 \mathrm{a}$ & $4,8 \mathrm{a}$ & $0,4 \mathrm{a}$ & $20,0 \mathrm{a}$ & $4,6 \mathrm{a}$ \\
\hline Plástico sem fungicidas para míldio ${ }^{\mathrm{a} /}$ & $50,0 \mathrm{a}$ & $4,2 \mathrm{a}$ & $0,5 \mathrm{a}$ & $22,1 \mathrm{a}$ & $5,1 \mathrm{a}$ \\
\hline Plástico com $50 \%$ redução do padrão ${ }^{a /}$ & $53,1 \mathrm{a}$ & $4,4 \mathrm{a}$ & $0,5 \mathrm{a}$ & $22,6 \mathrm{a}$ & $5,0 \mathrm{a}$ \\
\hline Plástico com $75 \%$ redução do padrão ${ }^{a /}$ & $47,7 \mathrm{a}$ & $3,9 \mathrm{a}$ & $0,5 \mathrm{a}$ & $22,5 \mathrm{a}$ & $5,1 \mathrm{a}$ \\
\hline Plástico com fosfito e cobre ${ }^{a /}$ & $588 \mathrm{a}$ & 4,9 a & $0,5 \mathrm{a}$ & $21,1 \mathrm{a}$ & 4,9 a \\
\hline Plástico sem fungicidas & $51,4 \mathrm{a}$ & $4,3 \mathrm{a}$ & $0,4 \mathrm{a}$ & $21,0 \mathrm{a}$ & $5,1 \mathrm{a}$ \\
\hline $\mathrm{CV} \%$ & 23,31 & 23,32 & 22,66 & 8,62 & 9,14 \\
\hline
\end{tabular}

${ }^{a}$ : Com fungicidas para oídio.

Médias seguidas da mesma letra nas colunas não diferem entre si, pelo teste de Tukey $(p<0,05)$.

-: Tratamento sem produção de cachos devido à ocorrência de míldio. 
TABELA 3 - Características da produção da videira 'BRS Clara' sobre os porta-enxertos 'IAC 572 Jales' e 'IAC 766 Campinas', submetida a diferentes tipos de cultivo protegido e de tratamento fitossanitário, durante as safras de 2007 e 2008. Marialva-PR.

\begin{tabular}{|c|c|c|}
\hline \multirow[b]{2}{*}{ Porta-enxertos (PE) } & \multicolumn{2}{|c|}{ SAFRA 2007} \\
\hline & produção/planta b/(kg) & produtividade $^{\mathrm{c} /}(\mathrm{t} / \mathrm{ha})$ \\
\hline 'IAC 572 Jales' & $8,6 \mathrm{~b}$ & $7,2 \mathrm{~b}$ \\
\hline 'IAC 766 Campinas' & $15,1 \mathrm{a}$ & $12,6 \mathrm{a}$ \\
\hline \multicolumn{3}{|l|}{ Tipos de Cultivo Protegido (TC) } \\
\hline Tela plástica sem fungicidas para míldio ${ }^{a /}$ & $14,4 \mathrm{a}$ & $12,0 \mathrm{a}$ \\
\hline Tela plástica com fungicidas (padrão) ${ }^{a /}$ & $11,1 \mathrm{a}$ & 9,2 a \\
\hline Plástico sem fungicidas para míldio ${ }^{a /}$ & 12,4 a & 10,4 a \\
\hline Plástico com 50\% redução do padrão ${ }^{a /}$ & 11,4 a & $9,5 \mathrm{a}$ \\
\hline Plástico com $75 \%$ redução do padrão ${ }^{a /}$ & 10,9 a & $9,1 \mathrm{a}$ \\
\hline Plástico com fosfito e cobre ${ }^{a /}$ & $10,5 \mathrm{a}$ & 8,8 a \\
\hline Plástico sem fungicidas & $12,3 \mathrm{a}$ & $10,3 \mathrm{a}$ \\
\hline \multirow[t]{2}{*}{$\mathrm{CV} \%$} & 44,78 & 44,81 \\
\hline & \multicolumn{2}{|c|}{ SAFRA 2008} \\
\hline
\end{tabular}

Porta-enxertos (PE)

produção/planta $^{\mathrm{b} /(\mathrm{kg}) \quad \text { produtividade }}{ }^{\mathrm{c} /}(\mathrm{t} / \mathrm{ha})$

\begin{tabular}{lll}
\hline 'IAC 572 Jales' & $23,7 \mathrm{a}$ & $19,6 \mathrm{a}$ \\
'IAC 766 Campinas' & $23,5 \mathrm{a}$ & $19,8 \mathrm{a}$ \\
\hline
\end{tabular}

\section{Tipos de Cultivo Protegido (TC)}

Tela plástica sem fungicidas para míldio ${ }^{a}$

Tela plástica com fungicidas (padrão) ${ }^{a /}$ $22,8 \mathrm{ab}$

$18,9 \mathrm{ab}$

Plástico sem fungicidas para míldio ${ }^{a}$

$22,9 \mathrm{ab}$

$19,1 \mathrm{ab}$

Plástico com $50 \%$ redução do padrão ${ }^{\mathrm{a} /}$

27,7 a

$23,1 \mathrm{a}$

Plástico com $75 \%$ redução do padrão ${ }^{a /}$

23,1 ab

$19,3 \mathrm{ab}$

Plástico com fosfito e cobre ${ }^{a /}$

$26,4 \mathrm{ab}$

$21,9 \mathrm{ab}$

Plástico sem fungicidas

$18,9 \mathrm{~b}$

$15,7 \mathrm{~b}$

\begin{tabular}{l} 
CV\% \\
\hline a/: Com fungicidas para oídio. \\
b/: Estimativa em função do número médio de cachos por planta e da massa média dos cachos. \\
c/: Estimativa em função da produção média por planta e do número de plantas por hectare. \\
Médias seguidas da mesma letra nas colunas não diferem entre si, pelo teste de Tukey $(p<0,05)$. \\
-: Tratamento sem produção de cachos devido à ocorrência de míldio.
\end{tabular}


TABELA 4 - Características químicas das bagas da videira 'BRS Clara' sobre os porta-enxertos 'IAC 572 Jales' e 'IAC 766 Campinas', submetida a diferentes tipos de cultivo protegido e de tratamento fitossanitário, durante as safras de 2007 e 2008 . Marialva-PR.

\begin{tabular}{|c|c|c|c|}
\hline \multirow[b]{2}{*}{ Porta-enxertos (PE) } & \multicolumn{3}{|c|}{ SAFRA 2007} \\
\hline & $\begin{array}{c}\text { SS b/ } \\
\left({ }^{\circ} \text { Brix }\right)\end{array}$ & $\begin{array}{c}\mathrm{AT}^{\mathrm{c} /} \\
(\% \text { de ácido tartárico) }\end{array}$ & $\begin{array}{l}\text { relação } \\
\text { SS/AT }\end{array}$ \\
\hline 'IAC 572 Jales' & 19,2 a & $1,6 \mathrm{a}$ & $12,3 \mathrm{~b}$ \\
\hline 'IAC 766 Campinas' & 18,6 a & $1,2 \mathrm{~b}$ & $19,1 \mathrm{a}$ \\
\hline \multicolumn{4}{|l|}{ Tipos de Cultivo Protegido (TC) } \\
\hline Tela plástica sem fungicidas para míldio ${ }^{a /}$ & 18,8 a & $1,5 \mathrm{a}$ & 13,1 a \\
\hline Tela plástica com fungicidas (padrão) ${ }^{\mathrm{a} /}$ & 19,1 a & 1,4 a & $14,5 \mathrm{a}$ \\
\hline Plástico sem fungicidas para míldio ${ }^{\mathrm{a} /}$ & 19,2 a & 1,3 a & 18,2 a \\
\hline Plástico com $50 \%$ redução do padrão ${ }^{a /}$ & 18,7 a & $1,4 \mathrm{a}$ & $15,1 \mathrm{a}$ \\
\hline Plástico com $75 \%$ redução do padrão ${ }^{a /}$ & 19,1 a & 1,3 a & $18,7 \mathrm{a}$ \\
\hline Plástico com fosfito e cobre ${ }^{a /}$ & 18,7 a & $1,5 \mathrm{a}$ & 13,8 a \\
\hline Plástico sem fungicidas & 18,8 a & $1,4 \mathrm{a}$ & $16,7 \mathrm{a}$ \\
\hline \multirow[t]{2}{*}{$\mathrm{CV} \%$} & 6,75 & 30,30 & 58,12 \\
\hline & \multicolumn{3}{|c|}{ SAFRA 2008} \\
\hline Porta-enxertos (PE) & $\begin{array}{c}\text { SS b/ } \\
\left({ }^{\circ} \text { Brix }\right)\end{array}$ & $\frac{\mathrm{AT}^{\mathrm{c} /}}{(\% \text { de ácido tartárico) }}$ & $\begin{array}{l}\text { relação } \\
\text { SS/AT }\end{array}$ \\
\hline 'IAC 572 Jales' & $17,1 \mathrm{a}$ & $0,7 \mathrm{a}$ & $26,4 \mathrm{a}$ \\
\hline 'IAC 766 Campinas’ & $17,8 \mathrm{a}$ & $0,6 \mathrm{a}$ & $28,3 \mathrm{a}$ \\
\hline \multicolumn{4}{|l|}{ Tipos de Cultivo Protegido (TC) } \\
\hline Tela plástica sem fungicidas para míldio ${ }^{\mathrm{a} /}$ & - & - & - \\
\hline Tela plástica com fungicidas (padrão) ${ }^{a /}$ & $17,9 \mathrm{a}$ & $0,7 \mathrm{a}$ & $27,2 \mathrm{a}$ \\
\hline Plástico sem fungicidas para míldio ${ }^{a /}$ & $17,2 \mathrm{a}$ & $0,7 \mathrm{a}$ & $25,2 \mathrm{a}$ \\
\hline Plástico com $50 \%$ redução do padrão ${ }^{a /}$ & $17,5 \mathrm{a}$ & $0,6 \mathrm{ab}$ & $27,6 \mathrm{a}$ \\
\hline Plástico com $75 \%$ redução do padrão ${ }^{a /}$ & $17,4 \mathrm{a}$ & $0,6 a b$ & $27,0 \mathrm{a}$ \\
\hline Plástico com fosfito e cobre ${ }^{a /}$ & $17,2 \mathrm{a}$ & $0,5 \mathrm{~b}$ & $29,6 \mathrm{a}$ \\
\hline Plástico sem fungicidas & $17,6 \mathrm{a}$ & $0,6 \mathrm{ab}$ & $27,7 \mathrm{a}$ \\
\hline $\mathrm{CV} \%$ & 11,31 & 8,52 & 18,20 \\
\hline
\end{tabular}

a/: Com fungicidas para oídio.

${ }^{\mathrm{b} /}$ : Sólidos solúveis.

c/: Acidez titulável.

Médias seguidas da mesma letra nas colunas não diferem entre si, pelo teste de Tukey $(p<0,05)$. 
TABELA 5 - Ocorrência de míldio (Plasmopara viticola) nos cachos da videira 'BRS Clara' sobre os porta-enxertos 'IAC 572 Jales' e 'IAC 766 Campinas', submetida a diferentes tipos de cultivo protegido e de tratamento fitossanitário, durante a safra de 2008. Marialva-PR.

\begin{tabular}{|c|c|}
\hline Porta-enxertos (PE) & ocorrência de míldio nos cachos (\%) \\
\hline 'IAC 572 Jales' & $17,9 \mathrm{a}$ \\
\hline 'IAC 766 Campinas' & $18,7 \mathrm{a}$ \\
\hline \multicolumn{2}{|l|}{ Tipos de Cultivo Protegido (TC) } \\
\hline Tela plástica sem fungicidas para míldio ${ }^{\mathrm{a} /}$ & $100,0 \mathrm{a}$ \\
\hline Tela plástica com fungicidas (padrão) ${ }^{a /}$ & $15,0 \mathrm{~b}$ \\
\hline Plástico sem fungicidas para míldio ${ }^{\mathrm{a} /}$ & $0,0 \mathrm{~b}$ \\
\hline Plástico com $50 \%$ redução do padrão ${ }^{a /}$ & $0,0 \mathrm{~b}$ \\
\hline Plástico com $75 \%$ redução do padrão ${ }^{a /}$ & $3,1 \mathrm{~b}$ \\
\hline Plástico com fosfito e cobre ${ }^{a /}$ & $0,0 \mathrm{~b}$ \\
\hline Plástico sem fungicidas & $9,4 \mathrm{~b}$ \\
\hline $\mathrm{CV} \%$ & 64,2 \\
\hline
\end{tabular}

${ }^{a}$ : Com fungicidas para oídio.

Médias seguidas da mesma letra nas colunas não diferem entre si, pelo teste de Scott-Knott $(p<0,01)$.

As médias apresentadas não estão transformadas, no entanto, os agrupamentos dos tratamentos estimados pelos testes de média foram calculados com dados originais transformados para $\sqrt{\mathrm{x}+1}$.
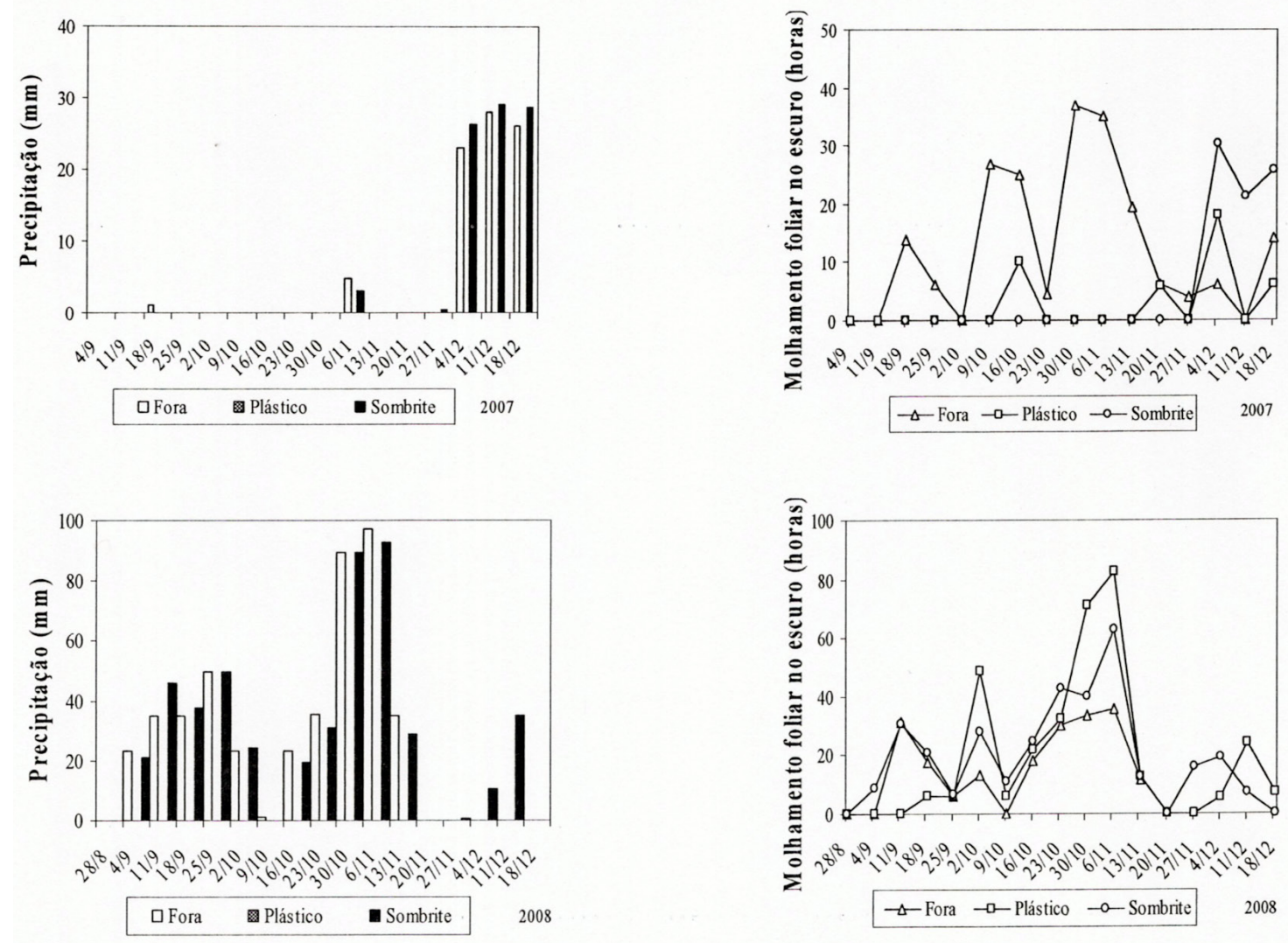

FIGURA 1 - Precipitação (mm) e molhamento foliar no escuro (h), obtidos em estações meteorológicas instaladas em vinhedo da 'BRS Clara' sobre os porta-enxertos 'IAC 572 Jales' e 'IAC 766 Campinas', submetidos a diferentes tipos de cultivo protegido e de tratamento fitossanitário, durante as safras de 2007 e 2008. Marialva-PR. 


\section{CONCLUSÕES}

1-A cobertura plástica não altera as principais características produtivas da videira 'BRS Clara', como número de cachos e produção por planta.

2-Os porta-enxertos 'IAC 766' e 'IAC 572' são indicados para a produção da uva 'BRS Clara' na região norte do Paraná.

3-A utilização da cobertura plástica permite a redução do número de aplicações de fungicidas para míldio no cultivo da uva 'BRS Clara'.

\section{REFERÊNCIAS}

ARAÚJO, J. L. P. Cultivo da videira. 2004. Disponível em: <http://www.sistemasdeprodução.cnptia. embrapa.br/fonteshtml/Uva/CultivodaVideira/custos.htm>. Acesso em: 18 maio 2009.

CAMARGO, U. A.; NACHTIGAL, J. C.; MAIA, J. D. G.; OLIVEIRA, P. R. D.; PROTAS, J. F. S. BRS Clara: nova cultivar de uva branca de mesa sem semente. Bento Gonçalves: Embrapa Uva e Vinho, 2003. 4p. (Comunicado Técnico, 46).

CARDOSO, L. S.; BERGAMASCHI, H.; COMIRAM, F.; CHAVARRIA, G.; MARODIN, G. A. B.; DALMAGO, G. A.; SANTOS, H. P.; MANDELLI, F. Alterações micrometeorológicas em vinhedos pelo uso de coberturas de plástico. Pesquisa Agropecuária Brasileira, Brasília, v.43, n.4, p.441-447, 2008.

CHAVARRIA, G.; SANTOS, H. P.; FELIPPETO, J.; MARODIN, G. A. B.; BERGAMASCHI, H.; CARDOSO, L. S.; FIALHO, F. B. Relações hídricas e trocas gasosas em vinhedo sob cobertura plástica. Revista Brasileira de Fruticultura, Jaboticabal, v.30, n.4, p.1022-1029, 2008.

CHAVARRIA, G.; SANTOS, H. P.; ZANUS, M. C.; MARODIN, G. A. B.; CHALAÇA, M. Z.; ZORZAN, C. Maturação de uvas 'Moscato Giallo' sob cultivo protegido. Revista Brasileira de Fruticultura, Jaboticabal, v.32, n.1, p.151-160, 2010.

CHAVARRIA, G.; SANTOS, H. P.; SÔNEGO, O. R.; MARODIN, G. A. B.; BERGAMASCHI, H.; CARDOSO, L. S. Incidência de doenças e necessidade de controle em cultivo protegido de videira. Revista Brasileira de Fruticultura, Jaboticabal, v.29, n.3, p.477-482, 2007.

FELDBERG, N. P.; REGINA, M. A.; DIAS, M. S. C. Desempenho agronômico das videiras 'Crimson Seedless' e 'Superior Seedless' no norte de Minas Gerais. Pesquisa Agropecuária Brasileira, Brasília, v.42, n.6, p.777-783, 2007.
FERREIRA, D. F. Manual do sistema Sisvar para análises estatísticas. Lavras: UFLA, 2000. 66p.

FERREIRA, M. A.; PEDRO JÚNIOR, M. J.; SANTOS, A. O.; HERNANDES, J. L. Modificação parcial do ambiente de cultivo da videira 'Cabernet Sauvignon' sobre diferentes porta-enxertos: efeito sobre a produção e o teor de sólidos solúveis. Bragantia, Campinas, v.63, n.3, p.439-445, 2004

KISHINO, A. Y.; GENTA, W.; ROBERTO, S. R. Introdução: produção de uva no Paraná. In: KISHINO, A. Y.; CARVALHO, S. L. C. de; ROBERTO, S. R. Viticultura tropical: o sistema de produção do Paraná. Londrina: Iapar, 2007. p.22-23.

LEÃO, P. C. S. Comportamento das variedades de uva sem sementes Crimson Seedless e Fantasy Seedless no Submédio do Vale do São Francisco. Revista Científica Rural, Bagé, v.7, n.1, p.85-94, 2002.

LULU, J.; CASTRO, J. V.; PEDRO JÚNIOR, M. J. Efeito do microclima na qualidade da uva de mesa 'Romana' (A1105) cultivada sob cobertura plástica. Revista Brasileira de Fruticultura, Jaboticabal, v.27, n.3, p.422-425, 2005.

MADDEN, L. V.; LALANCETTE, N.; HUGHES, G.; WILSON, L. L. Evaluation of a disease warning system for downy mildew of grapes. Plant Disease, St Paul, v.84, p.549-554, 2000

MOTA, C. S.; AMARANTE, C. V. T.; SANTOS, H. P.; ZANARDI, O. Z. Comportamento vegetativo e produtivo de videiras 'Cabernet Sauvignon' cultivadas sob cobertura plástica. Revista Brasileira de Fruticultura, Jaboticabal, v.30, n.1, p.148-153, 2008.

NACHTIGAL, J. C. Uvas sem sementes. Revista Brasileira de Fruticultura, Jaboticabal, v.27, n.1, p.1, 2005 .

TAGLIARI, P. S. Potencial para produção de vinhos nas regiões mais altas de Santa Catarina. Agropecuária Catarinense, Florianópolis, v.16, n.2, p.26-33, 2003.

TESSMANN, D. J.; VIDA, J. B.; GENTA, W.; KISHINO, A. Y. Doenças e seu manejo: doenças fúngicas. In: KISHINO, A. Y.; CARVALHO, S. L. C. de; ROBERTO, S. R. Viticultura tropical: o sistema de produção do Paraná. Londrina: Iapar, 2007. p.255-287. 